Virginia Commonwealth University vCU Scholars Compass

1998

\title{
A Comparison of Four Treatments for Generalized Convulsive Status Epilepticus
}

David M. Treiman, M.D.

Veterans Affairs Medical Centers in West Los Angeles

Patti D. Meyers, M.P.A.

Veterans Affairs Medical Centers in West Los Angeles

Nancy Y. Walton, Ph.D.

Veterans Affairs Medical Centers in West Los Angeles

See next page for additional authors

Follow this and additional works at: http://scholarscompass.vcu.edu/vcuhealth_pubs

Part of the Medicine and Health Sciences Commons

From The New England Journal of Medicine, Treiman, D.M., Meyers, P.D., Walton, N.Y., et al., A Comparison of Four Treatments for Generalized Convulsive Status Epilepticus, Vol. 339, Page 792, Copyright (C) 1998 Massachusetts Medical Society. Reprinted with permission.

\section{Downloaded from}

http://scholarscompass.vcu.edu/vcuhealth_pubs/18

This Article is brought to you for free and open access by the VCU Health at VCU Scholars Compass. It has been accepted for inclusion in VCU Health Publications by an authorized administrator of VCU Scholars Compass. For more information, please contact libcompass@vcu.edu. 


\section{Authors}

David M. Treiman , M.D.; Patti D. Meyers , M.P.A.; Nancy Y. Walton, Ph.D.; Joseph F. Collins , Sc.D.; Cindy Colling , R.Ph., M.S.; A. James Rowan , M.D.; Adrian Handforth , M.D.; Edward Faught , M.D.; Vincent P. Calabrese , M.D.; Basim M. Uthman , M.D.; R. Eugene Ramsay, M.D.; Meenal B. Mamdani , M.D.; Pratap Yagnik, M.D.; John C. Jones , M.D.; Elizabeth Barry, M.D.; Jane G. Boggs , M.D.; and Andres M. Kanner , M.D. 


\title{
A COMPARISON OF FOUR TREATMENTS FOR GENERALIZED CONVULSIVE STATUS EPILEPTICUS
}

\author{
David M. Treiman, M.D., Patti D. Meyers, M.P.A., Nancy Y. Walton, Ph.D., Joseph F. Collins, Sc.D., \\ Cindy Colling, R.Ph., M.S., A. James Rowan, M.D., Adrian Handforth, M.D., Edward Faught, M.D., \\ Vincent P. Calabrese, M.D., Basim M. Uthman, M.D., R. Eugene Ramsay, M.D., And Meenal B. Mamdani, M.D., \\ for the Veterans Affairs Status Epilepticus Cooperative Study Group*
}

\begin{abstract}
Background and Methods Although generalized convulsive status epilepticus is a life-threatening emergency, the best initial drug treatment is uncertain. We conducted a five-year randomized, doubleblind, multicenter trial of four intravenous regimens: diazepam (0.15 $\mathrm{mg}$ per kilogram of body weight) followed by phenytoin (18 $\mathrm{mg}$ per kilogram), lorazepam (0.1 mg per kilogram), phenobarbital (15 mg per kilogram), and phenytoin (18 mg per kilogram). Patients were classified as having either overt generalized status epilepticus (defined as easily visible generalized convulsions) or subtle status epilepticus (indicated by coma and ictal discharges on the electroencephalogram, with or without subtle convulsive movements such as rhythmic muscle twitches or tonic eye deviation). Treatment was considered successful when all motor and electroencephalographic seizure activity ceased within 20 minutes after the beginning of the drug infusion and there was no return of seizure activity during the next 40 minutes. Analyses were performed with data on only the 518 patients with verified generalized convulsive status epilepticus as well as with data on all 570 patients who were enrolled.
\end{abstract}

Results Three hundred eighty-four patients had a verified diagnosis of overt generalized convulsive status epilepticus. In this group, lorazepam was successful in 64.9 percent of those assigned to receive it, phenobarbital in 58.2 percent, diazepam and phenytoin in 55.8 percent, and phenytoin in 43.6 percent $(\mathrm{P}=0.02$ for the overall comparison among the four groups). Lorazepam was significantly superior to phenytoin in a pairwise comparison $(P=0.002)$. Among the 134 patients with a verified diagnosis of subtle generalized convulsive status epilepticus, no significant differences among the treatments were detected (range of success rates, 7.7 to 24.2 percent). In an intention-to-treat analysis, the differences among treatment groups were not significant, either among the patients with overt status epilepticus $(P=0.12)$ or among those with subtle status epilepticus $(P=0.91)$. There were no differences among the treatments with respect to recurrence during the 12hour study period, the incidence of adverse reactions, or the outcome at $\mathbf{3 0}$ days.

Conclusions As initial intravenous treatment for overt generalized convulsive status epilepticus, lorazepam is more effective than phenytoin. Although lorazepam is no more efficacious than phenobarbital or diazepam and phenytoin, it is easier to use. (N Engl J Med 1998;339:792-8.)

(c)1998, Massachusetts Medical Society.

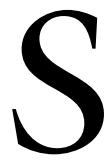

TATUS epilepticus is a life-threatening emergency that affects $65,000^{1}$ to $150,000^{2}$ people in the United States each year. Generalized convulsive status epilepticus is the most common and most dangerous type.

Phenobarbital, ${ }^{3-5}$ phenytoin, ${ }^{6-14}$ diazepam plus phenytoin, ${ }^{15,16}$ and lorazepam ${ }^{17-28}$ have been advocated for the initial treatment of generalized convulsive status epilepticus, and each is used by a substantial number of physicians. ${ }^{3}$ There are few data from controlled trials, however, to document the efficacy of these treatments, and they have not been directly compared. We therefore undertook this study to compare the efficacy of standard doses of these four drugs in the treatment of generalized convulsive status epilepticus.

\section{METHODS}

\section{Study Design}

In a double-blind study conducted at 16 Veterans Affairs medical centers and 6 affiliated university hospitals between July 1, 1990, and June 30, 1995, patients with generalized convulsive status epilepticus were randomly assigned to receive intravenous

From the Neurology Services of the Veterans Affairs Medical Centers in West Los Angeles, Calif. (D.M.T., P.D.M., N.Y.W., A.H.), Bronx, N.Y. (A.J.R.), Birmingham, Ala. (E.F.), Richmond, Va. (V.P.C.), Gainesville, Fla. (B.M.U.), and Miami (R.E.R.), and the Hines Veterans Affairs Medical Center, Chicago (M.B.M.); the Departments of Neurology of the University of California at Los Angeles School of Medicine, Los Angeles (D.M.T., N.Y.W.), Mount Sinai College of Medicine, New York (A.J.R.), the University of Alabama School of Medicine, Birmingham (E.F.), the Medical College of Virginia, Richmond (V.P.C.), the University of Florida School of Medicine, Gainesville (B.M.U.), the University of Miami School of Medicine, Miami (R.E.R.), and the Loyola University School of Medicine, Chicago (M.B.M.); the Veterans Affairs Cooperative Studies Program Coordinating Center, Perry Point, Md. (J.F.C.); and the Veterans Affairs Cooperative Studies Program Clinical Research Pharmacy Coordinating Center, Albuquerque, N.M. (C.C.). Address reprint requests to Dr. Treiman at the Department of Neurology, University of Medicine and Dentistry of New Jersey-Robert Wood Johnson Medical School, 97 Paterson St., New Brunswick, NJ 08901-0019.

Other authors were Pratap Yagnik, M.D. (Neurology Service, Veterans Affairs Medical Center, and Department of Neurology, Medical College of Pennsylvania - both in Philadelphia); John C. Jones, M.D. (Neurology Service, Veterans Affairs Medical Center, and Department of Neurology, University of Wisconsin School of Medicine - both in Madison); Elizabeth Barry, M.D. (Neurology Service, Veterans Affairs Medical Center, and Department of Neurology, University of Maryland School of Medicine both in Baltimore); Jane G. Boggs, M.D. (Neurology Service, Veterans Affairs Medical Center, and Department of Neurology, Medical College of Virginia - both in Richmond); and Andres M. Kanner, M.D. (Neurology Service, Veterans Affairs Medical Center, and Department of Neurology, University of Wisconsin School of Medicine - both in Madison).

* Other members of the study group are listed in the Appendix. 
treatment with lorazepam, phenobarbital, phenytoin, or diazepam followed by phenytoin.

Overt generalized convulsive status epilepticus was defined as recurrent convulsions without complete recovery between seizures, and subtle generalized convulsive status epilepticus as the stage of generalized convulsive status when the patient is in continuous coma but only subtle motor convulsions are seen. ${ }^{29} \mathrm{~Pa}-$ tients were classified as having one of these two types of status epilepticus according to the following operational definitions. Overt generalized convulsive status epilepticus was considered present when there were two or more generalized convulsions, without full recovery of consciousness between seizures, or continuous convulsive activity for more than 10 minutes (treatment after 10 minutes of continuous seizure activity was considered essential to protect against neuronal and systemic damage from ongoing seizure activity). Subtle generalized convulsive status epilepticus was considered present when the patient had coma and ictal discharges on the electroencephalogram, ${ }^{30}$ with or without subtle convulsive movements (rhythmic twitching of the arms, legs, trunk, or facial muscles; tonic eye deviation; or nystagmoid eye jerking). If the investigator required an electroencephalogram to diagnose generalized convulsive status epilepticus, the patient was considered to have subtle generalized convulsive status epilepticus.

The key criterion for study entry was evidence of overt or subtle generalized convulsive status epilepticus at the time of evaluation, regardless of prior drug treatment. Patients who had received treatment and whose seizures had stopped were not eligible for inclusion. Other exclusion criteria included status epilepticus of a type other than generalized convulsive, an age of less than 18 years, pregnancy, a neurologic emergency requiring immediate surgical intervention, and the presence of a specific contraindication to therapy with hydantoin, benzodiazepine, or barbiturate drugs. If patients with repeated episodes of generalized convulsive status epilepticus were inadvertently enrolled more than once, only the first episode was included in the analysis.

A blood sample was obtained before treatment for hematologic and serum-chemistry tests and for screening for antiepileptic drugs. Intravenous access was established with normal saline. The order of the treatments was determined by random assignment. Separate randomization schemes were used at each site for each type of status epilepticus. Treatment kits were placed at three or four locations within each participating center, and for each patient the lowest-numbered kit at the location nearest to the pa- tients was used. Electroencephalographic recording was started as soon as possible after the initiation of the protocol, but treatment was never delayed until the electroencephalogram could be obtained unless it was necessary to confirm the diagnosis. Blood pressure, heart rate, respiratory rate, level of consciousness, and seizure activity were recorded every 5 minutes for the first 20 minutes after the drug infusion began and then every 10 minutes for the next 40 minutes. Seizure activity and level of consciousness were recorded every hour thereafter until the completion of the 12-hour study period. Blood was obtained before the initial infusion, at the completion of the infusion, and 2 hours and 12 hours after the start of the infusion for the measurement of anticonvulsant-drug concentrations.

Treatment was considered successful if all clinical and electrical evidence of seizure activity stopped within 20 minutes after the start of the infusion and did not recur during the period from 20 to 60 minutes after the start of treatment. Electrical seizure activity included any of the five ictal patterns described previously. ${ }^{30}$

\section{Informed Consent}

From the institutional review board at each participating hospital, we obtained approval for the study and permission to waive the requirement for informed consent until after the initial randomized treatment. The rationale for the waiver was that the four study treatments were the four best treatments then available, and the patient was assumed to want the best available treatment. Because there were insufficient data to guide the selection of one treatment over another, any of the four treatments could be considered the best. Informed consent for continued participation in the study was obtained from the patient or a family member or other surrogate after initial treatment. Most patients were not competent to give informed consent during the 12-hour study period; some never recovered sufficiently to be able to provide consent. In such cases, consent was obtained from a surrogate, if one was available. State laws and institutional review board regulations regarding surrogate consent were adhered to at all sites. Consent was written, unless oral consent was permitted by a specific institution.

\section{Drug Treatment}

Phenytoin (Dilantin, Parke-Davis, Morris Plains, N.J.), phenobarbital (Spectrum Chemical, Gardena, Calif.), and diazepam

Table 1. Drug Doses, Rates of Administration, and Composition of Drug-Treatment Kits.

\begin{tabular}{|c|c|c|c|c|}
\hline VARIABLE & LORAZEPAM & Phenobarbital & $\begin{array}{c}\text { Diazepam AND } \\
\text { Phenytoin }\end{array}$ & Phenytoin \\
\hline Dose $(\mathrm{mg} / \mathrm{kg})$ & 0.1 & 15 & 0.15 and 18 & 18 \\
\hline $\begin{array}{l}\text { Maximal rate of administration } \\
\qquad(\mathrm{mg} / \mathrm{min})\end{array}$ & 2 & 100 & 5 and 50 & 50 \\
\hline $\begin{array}{l}\text { Drug-solution concentration } \\
\qquad(\mathrm{mg} / \mathrm{ml})^{*}\end{array}$ & 4 & 100 & 5 and 50 & 50 \\
\hline \multicolumn{5}{|l|}{ Contents of first treatment box } \\
\hline Tubex & Lorazepam & Dummy & Dummy & Dummy \\
\hline Vial A & Dummy & Phenobarbital & Diazepam & Phenytoin \\
\hline Vial B & Dummy & Phenobarbital & Phenytoin & Phenytoin \\
\hline Vial C & Dummy & Phenobarbital & Phenytoin & Phenytoin \\
\hline Vial D & Dummy & Dummy & Phenytoin & Phenytoin \\
\hline Vial E & Dummy & Dummy & Phenytoin & Dummy \\
\hline Active drug in second treatment box & Phenytoin & Phenytoin & Lorazepam & Lorazepam \\
\hline Active drug in third treatment box & Phenobarbital & Lorazepam & Phenobarbital & Phenobarbital \\
\hline
\end{tabular}

*To convert drug concentrations to millimoles per liter, multiply by the following: lorazepam, 3.11; phenobarbital, 4.31; diazepam, 3.51; and phenytoin, 3.96 . 
(Valium, Hoffmann-LaRoche, Nutley, N.J.) were packaged in identical vials at appropriate concentrations so each of the drugs could be administered at a rate of $1 \mathrm{ml}$ per minute to produce the maximal rates of drug infusion shown in Table 1. Lorazepam (Ativan, Wyeth-Ayerst, Philadelphia) was administered by means of Tubex injection at a maximal rate of $0.5 \mathrm{ml}$ per minute.

Identical-appearing drug-treatment kits were prepared for each drug regimen, with each kit containing a first, a second, and a third treatment box. The first treatment box consisted of one Tubex syringe and five vials, labeled A through E. A nomogram, based on the patient's weight, was used to determine the volume of solution administered from the Tubex and from each vial to produce the desired dose without compromising the blinded nature of the study. The Tubex solution and the solution from vial A were injected simultaneously. Tubexes and vials with active drug contained propylene glycol, as did dummy Tubexes; dummy vials contained normal saline. The second and third treatment boxes were provided to allow subsequent treatment, if necessary, without revealing the identity of the study drug. Active drugs in the second and third boxes for each treatment regimen are listed in Table 1 .

\section{Central Review}

We used a central procedure for review of electroencephalograms and data verification to ensure consistency among the hospitals in the diagnosis and classification of generalized convulsive status epilepticus and the determination of treatment success. A committee consisting of the study chairman, project director, and electroencephalographer reviewed all clinical data and electroencephalographic recordings obtained during the 12-hour study period. Differences of opinion between the central committee and investigators at the study sites were resolved by discussion. The review committee remained blinded to the identity of the treatment drug in each case until the review of all cases was completed.

\section{Statistical Analysis}

The study was designed to analyze the patients with overt and subtle generalized convulsive status epilepticus separately, because we anticipated a significant difference in outcome in the two groups. Analyses were performed both on an intention-to-treat basis, with all enrolled patients included, and with only patients included who had a verified diagnosis of generalized convulsive status epilepticus. The intention-to-treat analyses included patients who were mistakenly assigned to the wrong status group (e.g., overt instead of subtle status epilepticus), had other types of status epilepticus, or did not actually have status epilepticus. In the intention-to-treat analysis, patients in the last group were classified as having been successfully treated. For the analyses restricted to patients with verified diagnoses, patients were assigned to their correct status group (overt or subtle), as determined by the central review. Patients who did not have generalized convulsive status epilepticus were excluded from the verified-diagnosis analyses. Chi-square techniques were used to analyze rates of treatment success, recurrence, and adverse events. The alpha level was set at 0.05 for analyses of all four treatments, and a two-tailed alpha level of 0.01 was used to determine the significance of differences between any two regimens. ${ }^{31}$ Cochran-Mantel-Haenszel statistics $^{32}$ were used for the post hoc combined status-group analyses.

\section{RESULTS}

We attempted to enroll all eligible patients at each participating hospital. We screened 1705 patients during the study period; 570 were enrolled (395 with overt status epilepticus and 175 with subtle status epilepticus). Of the 1135 who were not enrolled, 113 were eligible but were not included because the
Table 2. Base-Line Characteristics of the 518 Patients with Verified Diagnoses, According to Type of Generalized Convulsive Status Epilepticus.*

\begin{tabular}{lcc}
\hline CHARACTERISTIC & $\begin{array}{c}\text { OVERT } \\
\text { (N=384) }\end{array}$ & $\begin{array}{c}\text { SUBTLE } \\
\text { (N= 134) }\end{array}$ \\
Age (yr) & $58.6 \pm 15.6$ & $62.0 \pm 15.1$ \\
Veteran (\%) & 70.1 & 80.6 \\
Male sex (\%) & 82.3 & 85.1 \\
Not previously treated for current episode (\%) & 51.3 & 51.5 \\
History of acute seizures (\%) & 54.2 & 25.4 \\
History of epilepsy (\%) & 42.4 & 12.7 \\
History of status epilepticus (\%) & 12.8 & 4.5 \\
Median duration of status epilepticus at & 2.8 & 5.8 \\
$\quad$ enrollment (hr) & & \\
Causal factors (\%) $\dagger$ & 69.5 & 34.3 \\
$\quad$ Remote neurologic cause & 27.3 & 37.3 \\
Acute neurologic cause & 32.0 & 56.7 \\
$\quad$ Life-threatening medical condition & 6.3 & 38.1 \\
Cardiopulmonary arrest & 6.3 & 5.2 \\
Toxic effects of therapeutic or recreational & & \\
$\quad$ drug & 6.5 & 0.7 \\
Alcohol withdrawal & & \\
\hline
\end{tabular}

*Plus-minus values are means $\pm S D$.

†Some patients had more than one causal factor.

study team was not called. The other 1022 were excluded for one or more of the following reasons: absence of generalized convulsive status epilepticus (868 patients), previous enrollment in the study (41), contraindication to phenytoin therapy (48), contraindication to barbiturate therapy (21), contraindication to benzodiazepine therapy (13), age of less than 18 years (1), pregnancy (1), presence of a neurosurgical emergency (20), and other reasons (236). Fifty-two of the 570 enrolled patients did not have generalized convulsive status epilepticus at the time of randomization. In addition, 18 patients classified as having subtle status epilepticus at randomization actually had overt generalized convulsive status epilepticus. As a result, 384 patients with verified overt status epilepticus and 134 with subtle status epilepticus (total, 518) were included in all the analyses performed in the verified-diagnosis group; all $\mathbf{5 7 0}$ enrolled patients were included in the intention-totreat analysis. Data on efficacy could not be obtained for five patients with overt status epilepticus.

Table 2 summarizes the characteristics of the patients with verified diagnoses. Although there were no significant differences among the four drug-treatment groups in any of the characteristics we examined (data not shown), patients with overt and subtle status epilepticus differed significantly with respect to age, race, current use of anticonvulsants, history of seizures, cause of status epilepticus, functional status before the current episode, whether or not they were veterans, the part of the hospital where treatment took place (emergency room, ward, or in- 
Table 3. Doses, Serum Drug Concentrations after First Drug Infusion, and Length of Drug Infusion.*

\begin{tabular}{lccc}
\hline REGimen & Dose & $\begin{array}{c}\text { SERUM } \\
\text { Concentration }\end{array}$ & $\begin{array}{c}\text { Length of } \\
\text { InFusiont }\end{array}$ \\
& $\mathrm{mg} / \mathrm{kg}$ & $\mu \mathrm{g} / \mathrm{ml}$ & $\mathrm{min}$ \\
Lorazepam & $0.10 \pm 0.01$ & $0.231 \pm 0.299$ & $4.7 \pm 7.2$ \\
Phenobarbital & $14.96 \pm 2.53$ & $31.2 \pm 37.2$ & $16.6 \pm 11.5$ \\
Diazepam and phenytoin & $0.15 \pm 0.02$ & $0.245 \pm 0.307$ & $42.0 \pm 38.1$ \\
& and & and & \\
& $15.08 \pm 4.84$ & $31.8 \pm 19.2$ & \\
Phenytoin & $16.02 \pm 3.21$ & $30.0 \pm 13.6$ & $33.0 \pm 20.1$
\end{tabular}

*Values are means \pm SD. To convert concentrations to micromoles per liter, multiply by the following: lorazepam, 3.11; phenobarbital, 4.31 ; diazepam, 3.51; and phenytoin, 3.96 .

$\dagger \mathrm{P}<0.001$ for the differences among the drug regimens

tensive care unit), history of status epilepticus, history of excessive alcohol use, and duration of status epilepticus.

Table 3 gives the mean doses, serum concentrations after infusion, and length of time necessary to complete infusion for each of the four initial treatments. Lorazepam required the least time to infuse $(\mathrm{P}<0.001$ in paired comparisons $)$; the treatments that included phenytoin took the longest $(\mathrm{P}<0.001)$.

Figure 1 presents the results of the four treatment regimens with respect to efficacy. In the analysis of the 518 patients with verified diagnoses (Fig. 1A), the first treatment regimen was successful in $\mathbf{5 5 . 5}$ percent of patients with overt status epilepticus, but in only 14.9 percent of those with subtle status epilepticus. Among the patients with overt status epilepticus, chi-square analysis showed a significant difference overall $(\mathrm{P}=0.02)$ in the frequency of success among the four treatments, but no differences were detected in the group with subtle status epilepticus $(\mathrm{P}=0.18)$. Lorazepam was effective significantly more often than phenytoin $(\mathrm{P}=0.002)$ in patients with overt status epilepticus. Other pairwise comparisons did not show significant differences between individual treatments.

When the two groups were combined in a post hoc analysis, lorazepam was successful as the first treatment in $\mathbf{5 2 . 2}$ percent of the patients to whom it was administered, phenobarbital in 49.2 percent, diazepam followed by phenytoin in 43.1 percent, and phenytoin alone in 36.8 percent. Chi-square analysis revealed a significant difference $(\mathrm{P}=0.008)$ in the frequency of success among treatments. In paired comparisons, lorazepam was effective more often than phenytoin $(\mathrm{P}=0.001)$. The difference in efficacy between phenobarbital and phenytoin approached significance $(\mathrm{P}=0.02)$. The results of the intention-to-treat analysis (Fig. 1B) were similar, but

\section{A Patients with Verified Diagnoses}

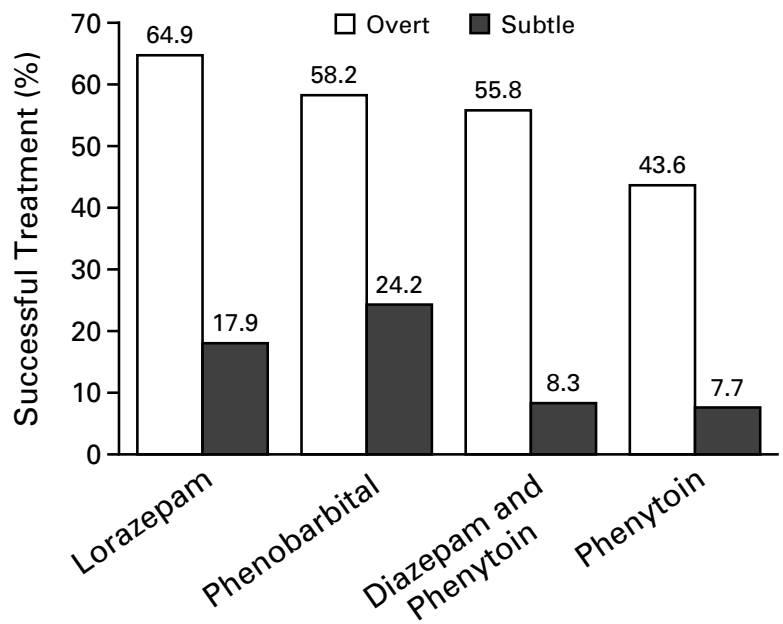

No. of PATIENTS

$\begin{array}{llllr}\text { Overt } & 97 & 91 & 95 & 101 \\ \text { Subtle } & 39 & 33 & 36 & 26\end{array}$

B All Enrolled Patients

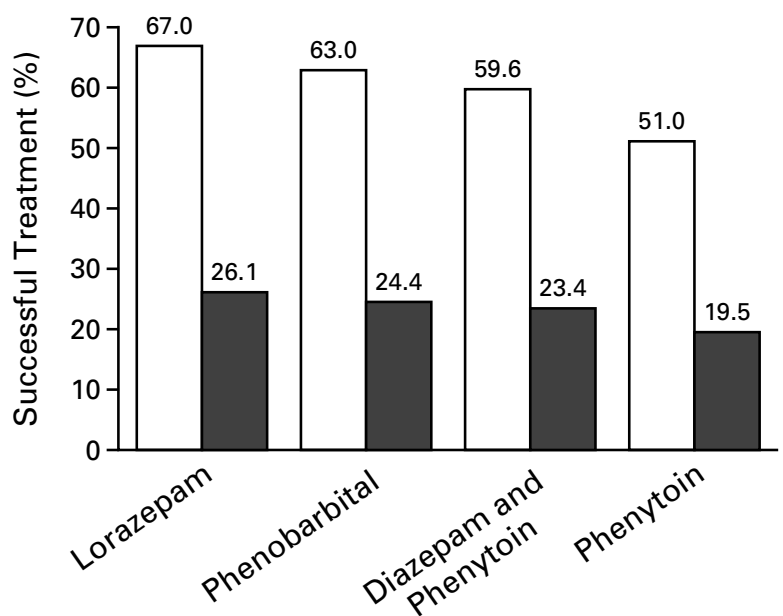

No. OF PATIENTS

$\begin{array}{lrrrr}\text { Overt } & 100 & 92 & 99 & 104 \\ \text { Subtle } & 46 & 41 & 47 & 41\end{array}$

Figure 1. Rate of Successful Initial Treatment with Each of the Four Regimens.

Open bars indicate patients with overt generalized convulsive status epilepticus, and solid bars those with subtle status epilepticus. Panel A shows the results of our analysis of patients with a verified diagnosis of generalized convulsive status epilepticus. Among the patients with overt status epilepticus, differences in the frequency of success among the treatments were significant $(P=0.02)$; in pairwise comparisons, lorazepam was effective significantly more often than phenytoin $(P=0.002)$. Panel $B$ shows the results of the intention-to-treat analysis. The differences in the frequency of success among the treatment groups were not significant. The success rate for each treatment is indicated above the bars. 
differences between groups were not significant for either the patients with overt status epilepticus $(\mathrm{P}=$ $0.12)$ or those with subtle status epilepticus $(\mathrm{P}=$ 0.91 ). In the verified-diagnosis analysis, status epilepticus recurred during the 12-hour study period in 11 percent ( 24 of 213 ) of patients with successfully treated overt status epilepticus and 20 percent ( 4 of 20 ) of successfully treated patients with subtle cases. There were no significant differences in the rates of recurrence among the four treatments for either the patients with a verified diagnosis of overt generalized convulsive status epilepticus or those with verified subtle status epilepticus.

The commonly reported side effects of treatment are shown in Table 4 . There were no significant differences among the four treatments in either group (those with overt or subtle generalized convulsive status epilepticus). However, hypotension requiring treatment occurred more often in the patients with subtle status epilepticus than in those with overt status epilepticus $(\mathrm{P}<0.001)$. Sixty-seven of the patients with overt status epilepticus (17 percent) regained full consciousness before the end of the 12hour study period, with no significant differences among the four treatment groups $(\mathrm{P}=0.59)$. None of the patients with subtle status epilepticus completely regained consciousness during the 12 -hour study period.

Outcomes 30 days after treatment were significantly worse $(\mathrm{P}<0.001)$ for patients with subtle status epilepticus. At 30 days, 50.1 percent of patients with overt status epilepticus had been discharged from the hospital, as compared with 8.8 percent of patients with subtle status epilepticus; 22.9 percent of those with overt status epilepticus were still in the hospital, as compared with 26.5 percent of those with subtle status epilepticus; mortality rates were

Table 4. Frequency of Common Drug-Related Side Effects among the 518 Patients with Verified Diagnoses.

\begin{tabular}{|c|c|c|c|c|}
\hline $\begin{array}{c}\text { Type of } \\
\text { Generalized } \\
\text { Convulsive } \\
\text { Status Epilepticus } \\
\text { and Side EfFect }\end{array}$ & LORAZEPAM & Phenobarbital & $\begin{array}{c}\text { DiaZEPAM } \\
\text { AND } \\
\text { PhenYtoIn }\end{array}$ & Phenytoin \\
\hline \multicolumn{5}{|l|}{ Overt } \\
\hline $\begin{array}{l}\text { No. of patients } \\
\text { Hypoventilation (\%) } \\
\text { Hypotension (\%) } \\
\text { Cardiac-rhythm } \\
\quad \text { disturbance }(\%)\end{array}$ & $\begin{array}{r}97 \\
10.3 \\
25.8 \\
7.2\end{array}$ & $\begin{array}{l}91 \\
13.2 \\
34.1 \\
3.3\end{array}$ & $\begin{array}{r}95 \\
16.8 \\
31.6 \\
2.1\end{array}$ & $\begin{array}{r}101 \\
9.9 \\
27.0 \\
6.9\end{array}$ \\
\hline \multicolumn{5}{|l|}{ Subtle } \\
\hline $\begin{array}{l}\text { No. of patients } \\
\text { Hypoventilation (\%) } \\
\text { Hypotension (\%) } \\
\text { Cardiac-rhythm } \\
\text { disturbance (\%) }\end{array}$ & $\begin{array}{r}39 \\
12.8 \\
59.0 \\
7.7\end{array}$ & $\begin{array}{r}33 \\
15.2 \\
48.5 \\
9.1\end{array}$ & $\begin{array}{r}36 \\
2.9 \\
58.3 \\
5.6\end{array}$ & $\begin{array}{r}26 \\
7.7 \\
57.7 \\
0.0\end{array}$ \\
\hline
\end{tabular}

27.0 percent and 64.7 percent, respectively. There were no significant differences in outcome at 30 days among the four treatments for either the patients with overt status epilepticus or those with subtle status epilepticus. In both the overt and subtle status epilepticus groups, however, patients successfully treated with the first study drug had a better prognosis than did those in whom the first treatment was not successful (for patients with overt status epilepticus, $\mathrm{P}<0.001$; for those with subtle status epilepticus, $\mathrm{P}=0.01)$. Among patients with overt and subtle status epilepticus, mortality was twice as high for patients whose status was not controlled with the first drug as for those in whom the first treatment was successful. No other follow-up data were collected.

\section{DISCUSSION}

Our results show that lorazepam is more likely than phenytoin to be successful when used as the initial intravenous treatment for overt generalized convulsive status epilepticus. Although this study was sponsored by the Department of Veterans Affairs, 30 percent of the patients with overt status epilepticus were not veterans, and 18 percent were female, suggesting that our results are widely applicable to the treatment of generalized convulsive status epilepticus in adults.

The lower overall efficacy rates reported here, as compared with data from earlier studies, ${ }^{10-14,16-26}$ probably result from our including only patients with generalized convulsive status epilepticus and our use of a stringent definition of treatment success: cessation of all clinical and electrical evidence of seizure activity within 20 minutes, with no recurrence during the next 40 minutes. The use of a period longer than 20 minutes in the definition of treatment success was discussed during the development of this protocol, but it was rejected as exposing patients to unnecessary risk. It is desirable that medications for this condition be given in a short intravenous infusion and enter the brain rapidly during infusion. Lorazepam, the most effective drug in the paired comparisons, required the least time to administer. It could be argued that the 20-minute time limit constituted a disadvantage for phenytoin, because of its mandatory slow infusion rate. On the other hand, phenobarbital, which enters the brain slowly, ${ }^{33}$ was not significantly less effective than lorazepam in patients with overt generalized convulsive status epilepticus. Thus, it appears that the 20 -minute criterion for success does not in itself explain the differences we found.

We found no differences among the treatments in the frequency of recurrence of overt or subtle status epilepticus during the 12 -hour study period, suggesting that any of the four treatments, if successful, can protect equally well against recurrence. We also found no differences among the treatments in the 
incidence of hypotension requiring treatment, respiratory depression, or cardiac-rhythm disturbances in patients with either overt or subtle generalized convulsive status epilepticus. Thus, the risk of these adverse events appears similar with any of the four regimens if the drugs are administered at a safe rate to patients who have been appropriately screened for contraindications. Hypotension requiring treatment occurred more often in the patients with subtle generalized convulsive status epilepticus; this difference probably reflects the fact that patients with subtle status epilepticus were sicker than those with overt status epilepticus. Life-threatening medical conditions and cardiopulmonary arrest associated with generalized convulsive status epilepticus were more common among the patients with subtle status epilepticus (Table 2). The longer duration of status epilepticus in the patients with subtle cases (Table 2) may also have contributed to their greater susceptibility to drug-induced hypotension. Even patients with overt status epilepticus had a long delay between onset and treatment. Many of these episodes occurred at night, and paramedics were not called until after several seizures had occurred. For such patients, we considered status epilepticus to have begun at the time of the first seizure.

The rapidity of recovery of consciousness after treatment of status epilepticus is another clinically important factor when choosing a treatment regimen. The small number of patients who recovered fully within 12 hours suggests, however, that rapid, complete recovery may not be a realistic goal when treating generalized convulsive status epilepticus. The condition causing the episode and the effects of repetitive seizure activity also contribute to the impairment of consciousness. Identifying significant differences in the rates at which patients recover from drug-induced impairment of consciousness is difficult, because such a comparison would have to be made in a group of patients in whom the causative factors and duration and intensity of seizures before treatment were identical.

Overall, the patients with subtle generalized convulsive status epilepticus did much worse than those with overt generalized convulsive status epilepticus. The first drug treatment was successful in less than 15 percent of the patients with subtle status epilepticus, and their outcome was poor. Sixty-five percent of the patients with subtle status epilepticus died within 30 days after the episode, as compared with 27 percent of the patients with overt status epilepticus. Death in a patient with generalized convulsive status epilepticus is probably attributable largely to the underlying cause and duration of the episode. Nonetheless, successful treatment was significantly associated with improved outcomes in both patients with overt episodes and those with subtle episodes, although it is not clear whether the success of treat- ment was the cause or the effect of the better prognosis, or a combination of both.

Because even the best treatments were successful in only about two thirds of the patients with overt status epilepticus and one fourth of the patients with subtle status epilepticus, our study underscores the need for better methods of treating generalized convulsive status epilepticus and its underlying causes. Until new therapies become available, however, we recommend lorazepam for the initial intravenous treatment of generalized convulsive status epilepticus. Although lorazepam was no more efficacious than phenobarbital or than diazepam and phenytoin, it is easier to use.

Supported by the Department of Veterans Affairs Medical Research Service Cooperative Studies Program (CSP 265). Lorazepam and dummy lorazepam Tubexes used in the study were donated by Wyeth-Ayerst Laboratories.

Drs. Barry, Faught, Ramsay, Treiman, and Uthman serve as consultants to Parke-Davis. They and Drs. Boggs, Calabrese, Kanner, and Rowan also serve on the Parke-Davis speakers bureau. Dr. Treiman has also served as a consultant to Hoffmann-LaRoche and Wyeth-Ayerst.

We are indebted to the members of the Data Monitoring Committee (Timothy Pedley, M.D., Ilo Leppik, M.D., Eric Lothman, M.D., Ph.D. [deceased], Roger D. Porter, M.D., and Gerald VanBelle, Ph.D.) for their careful oversight of the progress of the trial; and to the Veterans Affairs Cooperative Studies Program Office staff (Daniel Deykin, M.D., Janet Gold, and Ping Huang, Ph.D.) for their support.

\section{APPENDIX}

Additional study participants included other investigators at the study sites: S.D. Collins, S. Dane, S.L. Fish, D.A. Hosford, R.I. Kuzniecky, M. Muxfeldt, H. Price, D. Rosenbaum, M.P. Remler, R.L. Ruff, P.A. Rutecki, M.V. Sowa, M.L. Tomyanovich, and B.J. Wilder; the study coordinators: D. Correll, A. Cugley, P. Encomienda, B. Gallo, K. Hall-Behrman, V. Hamilton, E. Hwang, P. Jarres, A. Mann, J. McWhorter, D. Meija, C. Mixon, M. Moroney, D. Mueller, R. Nemire, K. Ohara, R. Palovcik, R. Reed, M. Shove, L. Tuchman, L. Williams, and H.L. Yoon; staff of the study chairman's office: J. Bejaune, K. Fagan, and C. Stone; staff at the Veterans Affairs Cooperative Studies Program Coordinating Center: B. Calvert, R. Horney, D. Preston, and M. Rhoads; staff at the Veterans Affairs Cooperative Studies Program Clinical Research Pharmacy Coordinating Center: J. Peterson; and the staff of the central laboratory: E. Esteban, S. Gunawan, Q. Jiang, and V. Pham.

\section{REFERENCES}

1. Hauser WA. Status epilepticus: epidemiologic considerations. Neurology 1990;40:Suppl 2:9-13.

2. DeLorenzo RJ, Pellock JM, Towne AR, Boggs JG. Epidemiology of status epilepticus. J Clin Neurophysiol 1995;12:316-25.

3. Goldberg MA, McIntyre HB. Barbiturates in the treatment of status epilepticus. In: Delgado-Escueta AV, Wasterlain CG, Treiman DM, Porter RJ, eds. Status epilepticus: mechanisms of brain damage and treatment. Vol. 34 of Advances in neurology. New York: Raven Press, 1983:499-503.

4. Shaner DM, McCurdy SA, Herring MO, Gabor AJ. Treatment of status epilepticus: a prospective comparison of diazepam and phenytoin versus phenobarbital and optional phenytoin. Neurology 1988;38:202-7. 5. Crawford TO, Mitchell WG, Fishman LS, Snodgrass SR. Very-highdose phenobarbital for refractory status epilepticus in children. Neurology 1988;38:1035-40

6. Murphy JT, Schwab RS. Diphenylhydantoin (Dilantin) sodium used parenterally in control of convulsions: a five-year report. JAMA 1956;160: 385-8.

7. McWilliam PKA. Intravenous phenytoin sodium in continuous convulsions in children. Lancet 1958;2:1147-9.

8. Carter CH. Use of parenteral diphenylhydantoin (Dilantin) sodium in control of status epilepticus. Arch Neurol Psychiatry 1958;79:136-7. 
9. Wallis $\mathrm{W}$, Kutt $\mathrm{H}, \mathrm{McD}$ owell $\mathrm{F}$. Intravenous diphenylhydantoin in treatment of acute repetitive seizures. Neurology 1968;18:513-25.

10. Wilder BJ, Ramsay RE, Willmore LJ, Feussner GR, Perchalski RJ, Shumate JB Jr. Efficacy of intravenous phenytoin in the treatment of status epilepticus: kinetics of central nervous system penetration. Ann Neurol 1977; 1:511-8.

11. Cranford RE, Leppik IE, Patrick B, Anderson CB, Kostick B. Intravenous phenytoin in acute treatment of seizures. Neurology 1979;29:1474-9. 12. Wilder BJ. Efficacy of phenytoin in treatment of status epilepticus. In Delgado-Escueta AV, Wasterlain CG, Treiman DM, Porter RJ, eds. Status epilepticus: mechanisms of brain damage and treatment. Vol. 34 of Advances in neurology. New York: Raven Press, 1983:441-6.

13. Leppik IE, Patrick BK, Cranford RE. Treatment of acute seizures and status epilepticus with intravenous phenytoin. In: Delgado-Escueta AV,

Wasterlain CG, Treiman DM, Porter RJ, eds. Status epilepticus: mechanisms of brain damage and treatment. Vol. 34 of Advances in neurology. New York: Raven Press, 1983:447-51.

14. von Albert H-H. A new phenytoin infusion concentrate for status epilepticus. In: Delgado-Escueta AV, Wasterlain CG, Treiman DM, Porter RJ eds. Status epilepticus: mechanisms of brain damage and treatment. Vol. 34 of Advances in neurology. New York: Raven Press, 1983:453-6.

15. Sutherland JM, Tait H. The epilepsies: modern diagnosis and treatment. Edinburgh, Scotland: Livingstone, 1969.

16. Delgado-Escueta AV, Enrile-Bacsal F. Combination therapy for status epilepticus: intravenous diazepam and phenytoin. In: Delgado-Escueta AV, Wasterlain CG, Treiman DM, Porter RJ, eds. Status epilepticus: mechanisms of brain damage and treatment. Vol. 34 of Advances in neurology. New York: Raven Press, 1983:477-85.

17. Waltregny A, Dargent J. Preliminary study of parenteral lorazepam in status epilepticus. Acta Neurol Belg 1975;75:219-29.

18. Amand G, Evrard P. Le lorazepam injectable dans les états de mal épileptiques. Rev Electroencephalogr Neurophysiol Clin 1976;6:532-3.

19. DeOliverira RSP. Treatment of convulsive seizures with a new benzodiazepine, lorazepam. Rev Bras Clin Ter 1978;7:295-8.
20. Walker JE, Homan RW, Vasko MR, Crawford IL, Bell RD, Tasker WG. Lorazepam in status epilepticus. Ann Neurol 1979;6:207-13.

21. Griffith PA, Karp HR. Lorazepam in therapy for status epilepticus. Ann Neurol 1980;7:493.

22. Sorel L, Mechler L, Harmant J. Comparative trial of intravenous lorazepam and clonazepam in status epilepticus. Clin Ther 1981;4:326-36. 23. Leppik IE, Derivan AT, Homan RW, Walker J, Ramsay RE, Patrick B. Double-blind study of lorazepam and diazepam in status epilepticus. JAMA 1983;249:1452-4.

24. Levy RJ, Krall RL. Treatment of status epilepticus with lorazepam. Arch Neurol 1984;41:605-11.

25. Lacey DJ, Singer WD, Horwitz SJ, Gilmore H. Lorazepam therapy of status epilepticus in children and adolescents. J Pediatr 1986;108:771-

26. Crawford TO, Mitchell WG, Snodgrass SR. Lorazepam in childhood status epilepticus and serial seizures: effectiveness and tachyphylaxis. Neurology 1987;37:190-5.

27. Gabor AJ. Lorazepam versus phenobarbital: candidates for drug of choice for treatment of status epilepticus. J Epilepsy 1990;3:3-6.

28. Working Group on Status Epilepticus. Treatment of convulsive status epilepticus: recommendations of the Epilepsy Foundation of America's

Working Group on Status Epilepticus. JAMA 1993;270:854-9.

29. Treiman DM. Generalized convulsive status epilepticus in the adult. Epilepsia 1993;34:Suppl 1:S2-S11.

30. Treiman DM, Walton NY, Kendrick C. A progressive sequence of electroencephalographic changes during generalized convulsive status epilepticus. Epilepsy Res 1990;5:49-60.

31. Everitt BS. The analysis of contingency tables. London: Chapman \& Hall, 1977.

32. SAS/STAT user's guide, version 6. 4th ed. Cary, N.C.: SAS Institute, 1989.

33. Ramsay RE, Hammond EJ, Perchalski RJ, Wilder BJ. Brain uptake of phenytoin, phenobarbital, and diazepam. Arch Neurol 1979;36:535- 